\title{
Ascertaining the Impact of P:12 Engineering Education Initiatives: Student Impact through Teacher Impact
}

\author{
Dr. Marissa H. Forbes, University of Colorado, Boulder
}

Marissa Forbes is a research associate in the College of Engineering and Applied Science at the University of Colorado Boulder and lead editor of the TeachEngineering digital library. She previously taught middle school science and engineering and wrote K-12 STEM curricula while an NSF GK-12 graduate engineering fellow at CU. With a master's degree in civil engineering she went on to teach advanced placement and algebra-based physics for the Denver School of Science and Technology, where she also created and taught a year-long, design-based engineering course for seniors. Forbes earned her $\mathrm{PhD}$ in civil engineering, with an engineering education research focus.

\section{Dr. Jacquelyn F. Sullivan, University of Colorado, Boulder}

Jacquelyn Sullivan has led the multi-university TeachEngineering digital library project, now serving over 3.3M unique users (mostly teachers) annually, since its inception. She is founding co-director of the design-focused Engineering Plus degree program and CU Teach Engineering initiative in the University of Colorado Boulder's College of Engineering and Applied Science. With the intent of transforming engineering to broaden participation, Sullivan spearheaded design and launch of the Engineering GoldShirt Program at $\mathrm{CU}$ to provide a unique access pathway to engineering for high potential, next tier students not admitted through the standard admissions process; findings are very encouraging, and the program is being adapted at several other engineering colleges. Dr. Sullivan led the 2004 launch of ASEE's PreCollege Division, was conferred as an ASEE Fellow in 2011 and was awarded NAE's 2008 Gordon Prize for Innovation in Engineering and Technology Education.

\section{Denise W. Carlson, University of Colorado, Boulder}

Carlson is involved with a broad range of program implementation initiatives through the Integrated Teaching and Learning Program at the University of Colorado Boulder's College of Engineering and Applied Science, including the TeachEngineering Digital Library. She holds a BA in economics from the University of Michigan Ann Arbor. She serves as a contributing author and editor of many publications, proposals, presentations and curricula. 


\title{
Ascertaining the Impact of P-12 Engineering Education Initiatives: Student Impact through Teacher Impact
}

\begin{abstract}
The widespread need to address both science, technology, engineering and math (STEM) education and STEM workforce development is persistent. Underscored by the Next Generation Science Standards, demand is high for P-12 engineering-centered curricula. TeachEngineering is a free, standards-aligned NSF-funded digital library of more than 1,500 hands-on, design-rich K12 engineering lessons and activities. Beyond anonymous site-user counts, the impact of the TeachEngineering collection and outreach initiatives on the education of children and their teachers was previously unknown. Thus, the project team wrestled with the question of how to meaningfully ascertain classroom impacts of the digital engineering education library and - more broadly-how to ascertain the impacts of teacher-focused P-12 engineering education initiatives. In this paper, the authors approach the classroom impact question through probing self-reported differentials in 1) teachers' confidence in teaching engineering concepts and 2) changes in their teaching practices as a result of exposure to (and experiences with) K-12 engineering education resources and outreach opportunities. In 2016, four quantitative and qualitative surveys were implemented to probe the impact of the TeachEngineering digital library and outreach on four populations of K-12 teachers' confidence and practices, including the frequency with which they integrate engineering into their pre-college classrooms. Survey results document the teacher experience and perception of using hands-on K-12 engineering curricular materials in the classroom and help create a data-driven understanding of where to best invest future resources. The results suggest that the TeachEngineering curricular resources and outreach initiatives help teachers build confidence in their use of engineering curriculum and pedagogy in K-12 classrooms, impact their teaching practices, and increase their likelihood of teaching engineering in the classroom in the future.
\end{abstract}

\section{Introduction}

The Need

The connection between a technically literate workforce and the nation's global economic competitiveness, national security, and standard of living is well established, ${ }^{1,2,3,4,5}$ as is the integral role that science, technology, engineering and math (STEM) education expansion and advancement plays in that marriage. ${ }^{1,2}$ National leaders have repeatedly called for improved K12 STEM education, ${ }^{1,2}$ including the widespread adoption of design-based engineering education, ${ }^{4,5}$ the release of the engineering-infused national science standards, ${ }^{6}$ and efforts to improve the public perception and understanding of engineering. ${ }^{4,7}$

\section{TeachEngineering Digital Library}

TeachEngineering (teachengineering.org) is an NSF-funded, free, digital collection of more than 1,500 (and growing) original, hands-on K-12 engineering lessons and activities from 50 contributing programs, including contributions from 17 NSF GK-12 programs and 19 NSF Research Experience for Teachers (RET) programs. The TeachEngineering curricula are aligned with state, national and/or international science, mathematics and technology academic standards, and use engineering (increasingly focused on engineering design) as the vehicle to 
integrate science and mathematics concepts for K-12 students. The collection was accessed by more than 3.2M unique users in 2016, realizing $19 \%$ annual growth. Curriculum submitted for publication in the collection must be previously classroom-tested, and is externally reviewed by at least one teacher and one engineer as part of the publication quality assurance process.

TeachEngineering also provides professional development opportunities to teachers. In summer 2016, the project team conducted 10 seminars for RET programs (reaching 106 teachers) through interactive, Google Hangout webinars aimed at introducing teachers to the collection of engineering curricular resources and preparing them for-and ultimately guiding them throughthe submission-to-publication process for their own classroom-tested engineering curricula.

Since its launch, TeachEngineering has been a multi-university collaboration. ${ }^{8}$ At present, the project is based at the University of Colorado Boulder with collaboration from Oregon State University. The University of Colorado Boulder is also home to a customizable, design-based engineering program, Engineering Plus, that (among dozens of other possibilities) facilitates concurrent secondary math or science teacher-licensure preparation through $C U$ Teach Engineering, an engineering-degree based branch of the university's UTeach program. In its early education course in-class practicums, undergraduate engineering students in CU Teach Engineering use curriculum from the TeachEngineering digital library. Then, as they matriculate through the secondary math or science teacher licensure program, they also begin preparing their own curriculum for the TeachEngineering collection and are guided through the submission-topublication process by TeachEngineering editors.

For more than 10 years, the team at the University of Colorado Boulder has regularly held Integrating Engineering into Your STEM Curriculum professional development workshops during which hands-on activities from the TeachEngineering collection were modeled. Dozens of local STEM teachers attended the workshops and then continued on to become "engineering mentor teachers," hosting (and mentoring) GK-12 fellows and all university UTeach students as they complete the engineering lesson practicum requirement during their first education courses.

To summarize, beyond the broad dissemination of K-12 engineering curricula facilitated by the TeachEngineering site, the project team has participated in (and continues to conduct) various engineering education outreach initiatives.

\section{Impact}

Though the TeachEngineering project team has always been data-driven and engaged in project research, $, 10,11$ the team has also long side-stepped a deep dive into the vast, lurking "impact" question of how to meaningfully ascertain classroom impacts of the collection and-more broadly-how to ascertain the impacts of analogous teacher-focused P-12 engineering education initiatives. And, for good reason: when dealing with humans, capturing impact_- "a marked effect or influence" 12 - is an incredibly tall order. After all, human impact has an inherent inner experience component, which is invisible, sometimes private, and often impossible to describe with words. Following a trip to the beach, for example, imagine you are asked, how was it? Though you might rely on various qualitative sensory descriptions ("breezy," "hot," "beautiful"), feeling descriptions ("relaxing," "enjoyable"), or quantitative descriptions ("-1.1 low tide bottomed out at 4:53 p.m."; “70 ${ }^{\circ} \mathrm{F}, 68 \%$ humidity"), even as a poetic, data-equipped person, you 
would almost certainly be unable to fully communicate your inner experience of being at the beach and the impact that it had on you.

For TeachEngineering, like many other education initiatives, capturing the project's comprehensive impact hinges upon knitting together the pieces of individual (personal) impact, which themselves are nebulous and won't "hold a stitch." In the people-centered engineering education research arena, this is a considerable challenge facing researchers, and one that must be reconciled, often on a study-by-study basis.

\section{Individual Impact to Broad Impact}

Since 1997, NSF proposals have been evaluated in terms of intellectual merit and "broader impacts of the activities they propose to undertake." The NSF Director is required to "issue a report to Congress on the effect of the 'Broader Impacts' Criterion (BIC) on the types of activities funded by NSF." 13

Attention to broad impact "tends to occur when a proposal is being reviewed, rather than when the work is complete and is being reported," 14 and broad impact is "poorly articulated in some funded NSF proposals." 14 As NSF reports, "experience shows that while most proposers have little difficulty responding to the criterion relating to intellectual merit, many proposers have difficulty understanding how to frame the broader impacts of the activities they propose to undertake." 15 NSF provides five prompting questions for consideration to probe impact, paraphrased as pertaining to: 1) advancing discovery and understanding while promoting teaching, training and learning, 2) broadening the participation of underrepresented groups, 3) enhancing the infrastructure for research and education, 4) enhancing scientific and technological understanding, and 5) benefitting society. ${ }^{15}$

Engineering education researchers have long grappled with impact questions (in the ASEE conference archives alone, "impact" is mentioned in 568 titles; "measuring impact" is in 24 titles), and proposed various study-specific methods to probe impact. In one study, for example, student impact of project-based service learning (PBSL) was described through engineering college retention, participation by underrepresented students, fulfilment of ABET learning outcomes, and enhanced student preparation to practice engineering design. ${ }^{16}$ Another study that focused on measuring the impact of infusing entrepreneurship across engineering curriculum used measures of self-efficacy and locus of control. ${ }^{17}$ Student attitudes towards math and science were used to measure the impact of an elementary school engineering outreach program. ${ }^{18}$ More related to the teacher-focused TeachEngineering project, a study measuring the impact of a K-12 teacher internship program used pre- and post-surveys that asked teachers about the engineering design process, $21^{\text {st }}$ century skills, collaboration, and project-based learning; impact was reported as differentials between the pre- and post-surveys. ${ }^{19}$

\section{TeachEngineering Impact}

Compounding the enigmatic task of capturing personal impact, for TeachEngineering, an online collection with thousands of anonymous users each day, implementing pre- and post-surveys for a representative, random sampling of users is not (at least yet) possible. Instead, the team started with a quick, one-time, self-reported means of ascertaining 1) who is using the site and 2) the site's impact on teachers. 
Confidence is critical to teacher efficacy; even a neophyte instructor who does not yet feel confident must act confidently. ${ }^{20}$ Teacher confidence (both self-confidence and contentconfidence) oozes over into other key elements of teaching efficacy, such as "1) organization, structure, or clarity, 2) teacher-student interaction or rapport, 3) teaching skill, communication, or lecturing ability, 4) workload or course difficulty, and 5) grading examinations."20

In this paper, the authors approach the classroom impact question through exploring selfreported differentials in 1) teachers' confidence in teaching engineering concepts, and 2) changes in their teaching practices as a result of exposure to (and experiences with) K-12 engineering education resources and outreach opportunities.

\section{Methods}

\section{Surveys}

In 2016, four, 10-minute quantitative and qualitative Qualtrics surveys were implemented to probe the impact of the TeachEngineering digital library and outreach on four populations of K12 teachers' confidence and practices, including the frequency with which they integrated engineering into their classrooms (Table 1).

Table 1: Descriptions of the TeachEngineering (TE) impact surveys for four K-12 teacher populations.

\begin{tabular}{|l|l|}
\hline \multicolumn{1}{|c|}{ Survey } & \multicolumn{1}{c|}{ Population } \\
\hline TE site pop-up survey & $\begin{array}{l}\text { TeachEngineering.org users from September 27, 2016 to November 4, } \\
\text { 2016; } \mathrm{n}=\mathbf{3 7 3 , 8 4 0}\end{array}$ \\
\hline TE published author survey & $\begin{array}{l}\mathbf{3 8} \text { RET participant teachers whose curricula were published in the } \\
\text { collection between January 1, 2014 and September 19, 2016 }\end{array}$ \\
\hline TE RET outreach survey & $\begin{array}{l}\mathbf{1 0 6} \text { RET participants who attended a TE Google Hangout professional } \\
\text { development webinar in summer 2016 }\end{array}$ \\
\hline TE partner teacher survey & $\begin{array}{l}\mathbf{6 4} \mathrm{K}-12 \text { engineering mentor teachers who attended a hands-on } \\
\text { Integrating Engineering into Your STEM Curriculum professional } \\
\text { development workshop at the University of Colorado Boulder. }\end{array}$ \\
\hline
\end{tabular}

The surveys employed a combination of Likert-style, open-ended, and multiple-choice questions. The full TeachEngineering site pop-up survey is provided in Appendix A. The other three surveys covered the same content, but were modified to fit the context for each respective survey population.

\section{Data Analysis}

Though many researchers in the engineering education community treat Likert-style data as continuous (thereby reporting means and standard deviations), the authors take a more conservative statistical analysis approach and do not assume that level of data resolution. Instead, the data were treated as independent and nominal; and thus descriptive statistics were used to report on survey responses. Comparisons in Likert responses between groups were conducted using chi-square tests, after dichotomously grouping the data (i.e., separating those that were "highly confident" or "confident" from those that were "somewhat confident," "not very confident," or "not at all confident"). Tests were performed in Microsoft Excel. 


\section{Results and Discussion}

\section{TeachEngineering Site User Impact}

During the 39 days that the pop-up survey ran, the TeachEngineering site had 373,840 unique users; 386 elected to take the survey. This self-selected, proportionally tiny sampling cannot be considered representative of the population of site users as a whole, and the survey responses should not be extrapolated in that way. Rather, the results provide a first, rough-cut foray into learning about the people behind the screens, what they are doing with the TeachEngineering curricula, and how it is impacting them and their students (if they are, in fact, teaching in classrooms).

Just over half (51\%) of the respondents indicated that they were K-12 teachers (almost onequarter of whom had been teaching for at least 20 years), $6 \%$ indicated that they were "K-12 educator[s] in an informal learning setting," 3\% "engineer[s] engaged in K-12 outreach," and 2\% "community member[s] engaged in K-12 outreach." Another $38 \%$ of respondents identified with an "other" category, which included students, homeschool teachers, university faculty, community college instructors, as well as a self-described curriculum developer, a science instructional coach, and a teacher's aide.

The users varied in how often they reported teaching TeachEngineering curriculum in a classroom: "weekly" (20\%), "monthly" (15\%), "5-10 times a year" (11\%), "2-4 times a year" $(10 \%)$, "once a year" $(6 \%)$, and "never" (38\%). The authors were surprised by how many respondents browsing the collection (and volunteering for a survey) reported that they had "never" taught curriculum from the collection in a classroom, which prompts the question: what were they doing on TeachEngineering? Many of them also reported that it was their first time on the site, making it reasonable to guess that some hadn't yet had the opportunity to teach the curriculum in a classroom, but they might have had plans to do so in the future. Of those who had taught curriculum from the site in a classroom, $94 \%$ anticipated that they would continue doing so in the future.

Notable in terms of impact, more teachers were "highly confident" or "confident" in teaching engineering concepts to their students after using the TeachEngineering digital library curriculum $(85 \%)$ as compared to before $(35 \%)$ (chi-square $\mathrm{p}<0.001)$ (see Table 2 ).

The vast majority of respondents "strongly" (73\%) or "somewhat" (16\%) agreed that "after using the TeachEngineering digital library, [they] are more likely to integrate engineering concepts into [their] teaching." 
Table 2: Frequency counts of responses to two Likert-style survey questions that probed TeachEngineering (TE) site users' confidence in teaching engineering concepts.

\begin{tabular}{|l|c|c|c|c|c|}
\hline \multicolumn{1}{|c|}{ Survey Question } & $\begin{array}{c}\text { Not at all } \\
\text { confident }\end{array}$ & $\begin{array}{c}\text { Not very } \\
\text { confident }\end{array}$ & $\begin{array}{c}\text { Somewhat } \\
\text { confident }\end{array}$ & Confident & $\begin{array}{c}\text { Highly } \\
\text { confident }\end{array}$ \\
\hline $\begin{array}{l}\text { Before using the TE digital library } \\
\text { content, how confident were you in } \\
\text { teaching engineering concepts to } \\
\text { your students? (n=233) }\end{array}$ & $\begin{array}{c}20 \\
(9 \%)\end{array}$ & $\begin{array}{c}45 \\
(19 \%)\end{array}$ & $\begin{array}{c}87 \\
(37 \%)\end{array}$ & $\begin{array}{c}49 \\
(21 \%)\end{array}$ & $\begin{array}{c}32 \\
(14 \%)\end{array}$ \\
\hline $\begin{array}{l}\text { After using the TE digital library, } \\
\text { how confident are you in teaching } \\
\text { engineering concepts to your } \\
\text { students? }(\mathrm{n}=229)\end{array}$ & 6 & 2 & 27 & 106 & 88 \\
& $(3 \%)$ & $(1 \%)$ & $(12 \%)$ & $(46 \%)$ & $(38 \%)$ \\
\hline
\end{tabular}

Many users shared student benefits they had observed from using TeachEngineering curricula; student engagement was commonly mentioned:

"I am a physics teacher that has been looking for a more creative way to introduce vectors. My honors physics [students] are having a blast with the vector voyage activity!"

"Students are engaged and thinking. That's a definite plus!"

"My students are engaged in critical thinking, they have a lot to say about it and my principal is impressed."

"My students have loved using this curriculum. They have been so engaged and excited. They meet me at the door asking what we're going to do in science today!"

"Students are more engaged and excited about learning. Their conversations reflect what they are being taught."

"High engagement, rigorous questioning, critical thinking."

"Student growth can be observed throughout the year as students learn to work together cooperatively, plan effectively and think creatively."

"All of my students are actively engaged into [sic] the projects... They enjoy to the degree that I have no work habit or behavior problems."

"[Students] learn to be more self-motivated."

"The benefits that I see in my students are excitement about engineering, math, science, and arts. They want to come to school and learned [sic] about engineers. I see progress in mathematical strategies and problem solving."

As depicted by this sampler of respondent feedback, without the firsthand ability to ask students in the classrooms about their experiences with the TeachEngineering curricula, the authors found many teachers volunteering profuse, qualitative (and overwhelmingly positive), anecdotes about how they perceived their students to be impacted by the curriculum.

\section{TeachEngineering Published Teacher-Author Impact}

Of the 46 RET teacher-authors invited, 23 (43\%) responded to the published author survey. Each respondent had been teaching for at least three years; eight had 6-10 years of teaching experience, five had 11-20 years of experience, and four had been teaching for more than 20 years. The respondents taught a range of third- to twelfth-grade students. Sixteen said they had 
taught TeachEngineering curricula in their classrooms, but varied considerably in frequency ("510 times a year" $=4$; " $2-4$ times a year" $=5$; "once a year" $=6$ ); those that had not taught the curriculum cited reasons ranging from "because I didn't know about this resource" to "I have very limited time with my students and it's hard to add new content." Three-quarters of the respondents anticipated that they would use TeachEngineering engineering curricula in a classroom in the future.

Teachers found the submission-to-publication process "rigorous," "lengthy and detailed," and "very time consuming," although one teacher said it was "very easy," "encouraging and supportive," "efficient," and "respectful of time," while another teacher said it was "difficult at first but got easier with experience." Several teachers noted satisfaction in their final published products ("at the beginning it is difficult, but it is rewarding to see the final product"; "the editing and feedback process made my lesson much stronger").

In response to being asked how they were personally impacted by the submission-to-publication process, several teachers again cited a sense of accomplishment, while others ranged in their responses: "made me a better researcher and writer"; "[it] impacted me personally by giving me the confidence to submit more curriculum to TeachEngineering or to other publications. As well as, [sic] presenting my ideas to others"; "it helped [me] understand how to produce a quality activity"; "makes me, a teacher, feel empowered and confident in implementing more engineering practices"; "it has been the best learning experience I have had to produce highquality lessons that really impact students."

Also noteworthy in terms of impact, all but four teachers (80\%) either "strongly" or "somewhat" agreed that "after going through the TeachEngineering submission-to-publication process, [they] are more likely to integrate engineering concepts into [their] teaching.

\section{RET Outreach Impact}

Following their TeachEngineering Google Hangout seminars, 44 RET participants (42\%) responded to the survey. Almost two-thirds (61\%) had at least 11 years of teaching experience, and all but five were secondary math and science teachers. Forty of the teachers $(91 \%)$ had never heard of TeachEngineering before the webinar; 42 (95\%) anticipated that they would use curriculum from the site in their classrooms in the future - a high pay-off for a 60-minute time investment on the team's end.

\section{TeachEngineering Partner Teacher Impact}

Twenty-one TeachEngineering "engineering mentor teachers" (33\% of the 64 invited) responded to the impact survey. Each respondent had taught for at least six years; 13 had taught for 11 or more years; they were almost evenly split between elementary (8), middle (6), and high school (7), with one pre-K teacher. The teachers varied in how often they used TeachEngineering curriculum: "weekly" (1), "monthly" (5), "5-10 times a year" (1), "2-4 times a year" (8), "once a year" (3), "never" (3).

As with the site user survey respondents, many more partner teachers were "highly confident" or "confident" in teaching engineering concepts to their K-12 students after using the TeachEngineering digital library curriculum (78\%) as compared to before (42\%) (chi-square 
$\mathrm{p}=0.027$ ) (see Table 3). Eighty-nine percent of teachers "strongly" (12) or "somewhat" (4) agreed that "after using the TeachEngineering digital library, [they were] more likely to integrate engineering concepts into [their] teaching"; the remaining two teachers (three skipped the question) indicated that they "neither agree nor disagree." Eighteen teachers anticipated that they would use TeachEngineering curriculum in their classrooms in the future.

Some teachers reported that using the TeachEngineering digital library impacted their personal teaching philosophy or pedagogy, while others indicated that it served as more of a reinforcement: "[it has] improved my use of student talk time and collaboration"; "broadens the tool box for engaging students in problem-based learning"; "I am more apt to let my students create and build without too much direction. In a lot of cases they fail but it only makes them more determined to figure out a solution... before I would want everything they did to be guided and successful"; "it already goes along with what I believe about good teaching."

Table 3: Frequency counts of responses to two Likert-style survey questions that probed TeachEngineering (TE) engineering mentor teachers' confidence in teaching engineering concepts.

\begin{tabular}{|l|c|c|c|c|c|}
\hline \multicolumn{1}{|c|}{ Survey Question } & $\begin{array}{c}\text { Not at all } \\
\text { confident }\end{array}$ & $\begin{array}{c}\text { Not very } \\
\text { confident }\end{array}$ & $\begin{array}{c}\text { Somewhat } \\
\text { confident }\end{array}$ & Confident & $\begin{array}{c}\text { Highly } \\
\text { confident }\end{array}$ \\
\hline $\begin{array}{l}\text { Before using the TE digital library } \\
\text { content, how confident were you in } \\
\text { teaching engineering concepts to } \\
\text { your students? }\end{array}$ & 1 & 5 & 5 & 7 & 1 \\
\hline $\begin{array}{l}\text { After using the TE digital library, } \\
\text { how confident are you in teaching } \\
\text { engineering concepts to your } \\
\text { students? }\end{array}$ & 0 & 0 & 4 & 8 & 6 \\
\hline
\end{tabular}

Note: Two survey respondents chose not to answer the first question; three skipped the second question.

\section{Summary and Conclusions}

The results from this study suggest that both the TeachEngineering curricular resources and outreach training help teachers build confidence in their use of engineering in K-12 classrooms, impact their teaching practices, and increase their likelihood of teaching engineering in the classroom in the future. These findings indicate that continuing to invest project resources into adding new curricula to the digital library collection and expanding teacher outreach is money well spent.

User metrics tracking of the TeachEngineering collection reveals ongoing indicators of teacher usage. For example, site traffic patterns mirror the U.S. academic schedule, and print button clicks on the curriculum write-up pages indicate that a lot of printing is happening from the site.

The bulk of the curricular contents in the collection are themselves the resulting original and classroom-tested outcomes from multi-year National Science Foundation grantee programs at more than 40 U.S. university locations. These high-quality curricular gems from individual faculty-teacher partnerships scattered around the country are available to teachers nation-and world-wide since the collection serves as a dissemination venue for NSF through publishing and widely disseminating curricula developed through NSF K-12 engineering education grants. 
Working to understand classroom impact is tenuous. At its core, the TeachEngineering project is analogous to other teacher-focused P-12 engineering education initiatives; the authors hope that readers engaged in such projects find takeaways in the approach to probe classroom impact through exploring self-reported differentials in 1) teachers' confidence in teaching engineering concepts and 2) changes in their teaching practices as a result of exposure to (and experiences with) K-12 engineering education curriculum, pedagogy and outreach opportunities (i.e., how often they bring engineering concepts into the classroom).

Here you might ask, how does this increased teacher confidence in teaching engineering concepts impact students? This approach stops short of probing the impact for the ultimate student consumers. Though, while that question is not (yet) answered from our research, perhaps it is well answered on an intuitive level. Those readers who have spent many years as students themselves surely have an intuitive sense of the student-experienced difference between a teacher confident in his/her delivery and one who is unsure of him/herself. Teacher impact is a sustainable, year-to-year investment in student impact; teacher changes are seen — and felt — by students, and can have lasting (again, sometimes invisible, private, or non-verbalized) impact on individual students.

\section{Acknowledgements}

This work was funded by National Science Foundation grant no. EEC 1544495. However, these contents do not necessarily represent the policies of the NSF, and you should not assume endorsement by the federal government. IRB 15-0362

\section{References}

1. Institute of Medicine, National Academy of Engineering, and National Academy of Sciences. (2007). Rising above the Gathering Storm: Energizing and Employing America for a Brighter Economic Future. Washington, DC: The National Academies Press.

2. Institute of Medicine, National Academy of Engineering, and National Academy of Sciences. (2010). Rising above the Gathering Storm, Revisited: Rapidly Approaching Category 5. Washington, DC: The National Academies Press.

3. National Academy of Engineering. (2004). The Engineer of 2020: Visions of Engineering in the New Century. Washington, DC: National Academies Press.

4. National Academy of Engineering. (2005). Educating the Engineer of 2020: Adapting Engineering Education to the New Century. Washington, DC: National Academies Press.

5. National Academy of Engineering and National Research Council. (2009). Engineering in K-12 Education: Understanding the Status and Improving the Prospects. Washington, DC: The National Academies Press.

6. Next Generation Science Standards. Retrieved November 2016. http://www.nextgenscience.org/

7. National Academy of Engineering. (2008). Changing the Conversation: Messages for Improving Public Understanding of Engineering. Washington, DC: The National Academies Press.

8. TeachEngineering History. Retrieved November 2016. https://www.teachengineering.org/about/history

9. Sullivan, J.F., Cyr, M.N., Mooney, M.A., Reitsma, R.F., Shaw, N.C., Zarske, M.S. \& Klenk, P.A. (2005) "The TeachEngineering Digital Library: Engineering Comes Alive for K 12 Youth," 2005 ASEE Annual Conference \& Exhibition, Portland, OR, June. https://peer.asee.org/15513 
10. Reitsma, R.F., Klenk, P.A., Zarske, M.S. \& Sullivan, J.F. (2010) “Are French Fries and Grades Bad for You? Conflicting Evidence on How K 12 Teachers Search in a K-12 Digital Library,” 2010 ASEE Annual Conference \& Exposition, Louisville, KY, June. https://peer.asee.org/16838

11. Samson, C.C., Sullivan, J.F., Reitsma, R.F. \& Soltys, M.A. (2015) “The Relevance of K-12 Engineering Curricula to NGSS: An Analysis of TeachEngineering-NGSS Alignments (RTP Strand 1). 2015 ASEE Annual Conference \& Exposition, Seattle, WA, June. https://peer.asee.org/24905

12. Oxford English Dictionary. Retrieved November 2016. https://en.oxforddictionaries.com/definition/impact

13. Holbrook, J.B. \& Frodeman, R. (2007). "Answering NSF's Question: What Are the "Broader Impacts" of the Proposed Activity?” Professional Ethics Report, American Association for the Advancement of Science, 20(3), $1-3$.

14. Nadkarni, N.M. \& Stasch, A.E. (2013). "How Broad Are Our Broader Impacts? An Analysis of the National Science Foundation's Ecosystem Studies Program and the Broader Impacts Requirement." Frontiers in Ecology and the Environment, 11(1), 13-19.

15. National Science Foundation. Merit Review Broader Impacts Criterion: Representative Activities. Retrieved November 2016. https://www.nsf.gov/pubs/2002/nsf022/bicexamples.pdf

16. Bielefeldt, A.R., Paterson, K.G. \& Swan, C.W. (2009) "Measuring the Impacts of Project-Based Service Learning, ” 2009 ASEE Annual Conference \& Exposition, Austin, TX, June. https://peer.asee.org/5642

17. Borchers, A., Park, S.H., Harris, M., Riffe, W. \& Tavakoli, M. (2010) "Measuring the Impact of Entrepreneurship across the Curriculum," 2010 ASEE Annual Conference \& Exposition, Louisville, KY, June. https://peer.asee.org/16436

18. Lundstrom, K.L. \& Moskal, B.M. (2012) "Measuring the Impact of an Elementary School Outreach Program on Students' Attitudes toward Mathematics and Science," 2012 ASEE Annual Conference \& Exposition, San Antonio, TX, June. https://peer.asee.org/21681

19. Bowen, B. (2013) “Teachers in Industry: Measuring the Impact of a K-12 Teacher Internship Program,” 2013 ASEE Annual Conference \& Exposition, Atlanta, GA, June. https://peer.asee.org/22519

20. Eison, J. (1990) “Confidence in the Classroom: Ten Maxims for New Teachers," College Teaching, 38(1), 2125. 


\section{Appendix A: TeachEngineering Site Pop-Up Survey}

1. How often do you teach curriculum from the TeachEngineering digital library in a classroom?
a. Weekly
b. Monthly
c. 5-10 times a year
d. 2-4 times a year
e. Once a year
f. Never

2. Please tell us about any student benefits you see from using TeachEngineering curriculum.

3. Do you anticipate that you will continue to use TeachEngineering curriculum in your classroom?
a. Yes
b. No

4. Before using the TeachEngineering digital library, how confident were you in teaching engineering concepts to your students?
a. Highly confident
b. Confident
c. Somewhat confident
d. Not very confident
e. Not at all confident

5. After using the TeachEngineering digital library, how confident are you in teaching engineering concepts to your students?
a. Highly confident
b. Confident
c. Neutral
d. Not very confident
e. Not at all confident

6. Please rate your agreement with the following statement:

After using the TeachEngineering digital library, I am more likely to integrate engineering concepts into my teaching.
a. Strongly agree
b. Somewhat agree
c. Neither agree nor disagree
d. Somewhat disagree
e. Strongly disagree

7. What uses, value, benefits and impact have you experienced using the TeachEngineering digital library?

8. How has using the TeachEngineering digital library impacted your personal teaching philosophy or pedagogy?

9. How has using the TeachEngineering digital library helped prepare your students for college and career? 
10. Please tell us about yourself. I am a:
a. K-12 teacher
b. A K-12 educator in an informal learning setting
c. A community member engaged in K-12 outreach
d. An engineer engaged in K-12 outreach
e. Other (text box)

\section{[For $K$-12 teachers]}

11. For how many years have you been practicing as a teacher?
a. 1-2 years
b. 3-5 years
c. 6-10 years
d. 11-20 years
e. $20+$ years

12. Select all grade bands that you teach:
a. Pre-K
b. $\mathrm{K}-2$
c. $3-5$
d. $6-8$
e. $9-12$
f. Other

[For middle and high school teachers]

13. What subject areas do you teach? (Select all that apply)
a. Biology
b. Chemistry
c. Math
d. Physics
e. Engineering
f. STEM
g. Other (text box) 